\title{
ANISOTROPY OF MAGNETIC PROPERTIES IN NON-ORIENTED ELECTRICAL STEEL SHEETS
}

\author{
M. SHIOZAKI and Y. KUROSAKI \\ Hirohata $R \&$ \& Laboratories, Hirohata Works, Nippon Steel Corp. \\ Hirohata-Ku, Himeji City, Japan
}

\begin{abstract}
The anisotropy of magnetic properties in non-oriented electrical steel sheets can be evaluated by measuring Epstein specimens in the radial directions. The magnetic properties measured on ring cores are practically equal to the approximate values of magnetic properties determined by Epstein specimens in the radial directions. Non-oriented electrical steel sheets with anisotropy are not desirable for motors but are suitable for transformers and fluorescent lamp ballasts. The core loss and magnetic induction as measured with ring specimens are better with non-oriented electrical steel sheets with anisotropy than with non-oriented electrical steel sheets with random crystallographic orientation. This phenomenon depends on the texture change of the product.
\end{abstract}

KEY WORDS Electrical steel, non-oriented, Epstein strips, anisotropy, pole figures.

The magnetic properties of lamination steels and non-oriented electrical steels are measured on half-lengthwise and half-transverse Epstein specimens. ${ }^{1,2}$ The Epstein values are assumed to equal the mean values of magnetic properties measured in the radial directions of the rolling plane, but this assumption is not exactly correct because commercial non-oriented electrical steel sheets are more or less anisotropic with respect to magnetic properties in the rolling plane. It is, therefore, difficult to judge the superiority or inferiority of electrical steel sheets made by different processes from their Epstein magnetic properties alone.

\section{APPLICATION OF PREFERRED VALUES OF MAGNETIC PROPERTIES}

Non-oriented electrical steel sheets are used in many applications (Table 1). The stators of large rotating machines are built up of segmental laminations. The magnetic properties of the segmental stator laminations must be thus evaluated by the weighted average values of magnetic properties measured on $70 \%$ lengthwise and $30 \%$ transverse Epstein specimens. Non-oriented electrical steel sheets with uniform magnetic properties in the rolling plane are desirable for small and medium motors that are built up of ring-punched laminations. In this case, ring specimens should be preferably used for evaluating the magnetic properties of materials but are not usually used for this purpose. Static machines, such as EI lamination transformers and fluorescent lamp ballasts, require materials with superior magnetic properties in the rolling direction. Given the geometric designs involved, the magnetic properties of non-oriented electrical steel sheets for these applications should be measured on $75 \%$ lengthwise and 
Table 1 Applications and preferred magnetic evaluation methods of non-oriented electrical steel sheets.
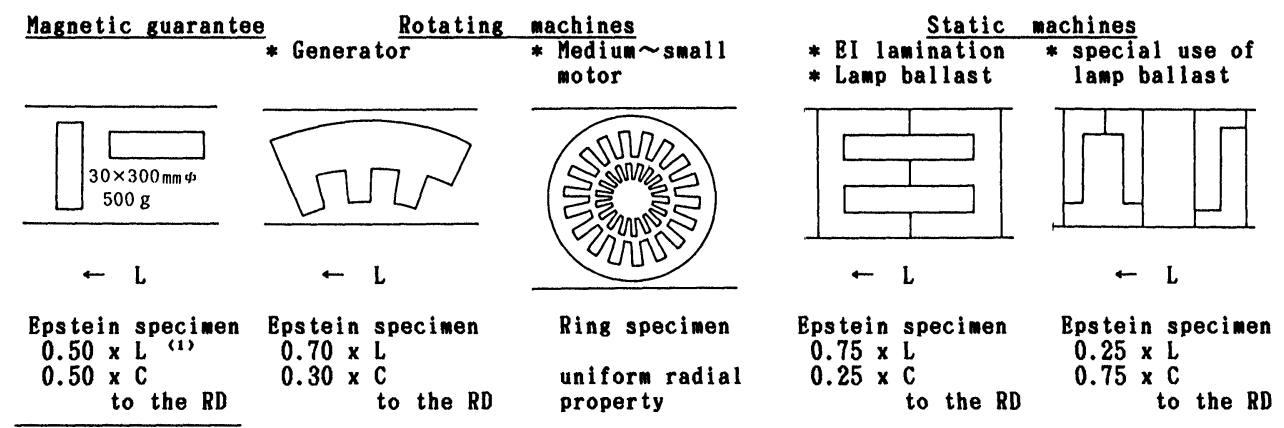

(1) L: rolling direction, C: transverse to the rolling direction

$25 \%$ transverse Epstein specimens. The cores of special types of ballasts are built up of laminations blanked from non-oriented electrical sheel sheets with good punchability. To minimize the punching stroke required, the magnetic properties in the transverse direction must be better than those of non-oriented electrical steel sheets for other applications.

\section{MAGNETIC PROPERTIES IN RADIAL DIRECTIONS}

\section{Calculation of Magnetic Properties in Specified Radial Directions}

Magnetic properties in the circumferential direction are generally determined on ring specimens, but ring specimens are disadvantageous in that they cannot be satisfactorily used to measure the magnetic properties in the radial directions of the rolling plane. It is convenient to measure the magnetic properties of non-oriented electrical steel sheets in the specified radial directions, check the anisotropy of the sheet in the rolling plane and approximately evaluate the magnetic properties of the sheet in the circumferential direction. The specimens used in this study are $0.50 \mathrm{~mm}$ thick non-oriented electrical steel sheets manufactured by different processes. Specimen A, containing $0.3 \% \mathrm{Si}$, was produced by a simple, single-reduction cold rolling process (hot rolling, cold rolling and annealing), while $0.3 \% \mathrm{Si}$ specimen $\mathrm{B}$ and $0.1 \% \mathrm{Si}$ specimen $\mathrm{C}$ were produced by a temper rolling or double-reduction cold rolling process (hot rolling, cold rolling, annealing and temper rolling). Specimen D, containing $2 \% \mathrm{Si}$, and specimen $\mathrm{E}$, containing no $\mathrm{Si}$, were made by a process composed of hot band annealing, cold rolling and annealing. The specimens were stress-relief annealed in a nitrogen atmosphere at $750^{\circ} \mathrm{C}$ for $2 \mathrm{~h}$ after punching. This stress-relief annealing is designed to remove the size effect of the punched lamination specimens. Magnetic induction and core loss were measured on $30 \times 300 \mathrm{~mm}(500 \mathrm{~g})$ Epstein specimens or $100 \times 100 \mathrm{~mm}$ single-strip specimens and ring cores. The single-strip specimens can be conveniently used to determine magnetic properties in each of the directions involved. The data of pole figures were measured at the surface, quarter point and center of the sheet thickness and 
were expressed as pole densities of the main crystal axes in the sheet normal direction $(\langle h k l\rangle / / \mathrm{ND})$.

Algebraic calculations. Approximate values of magnetic properties in the radial directions of the rolling plane can be calculated by algebraic equations for magnetic properties between the angles of 0 and $180^{\circ}$. If the range $(a, b)$ is divided into $2 n$ equal intervals, such as $x_{0}=a, x_{1}$ and $x_{2 n}=b$, and $y_{k}=f\left(x_{k}\right)(k=$ $0,1, \ldots, 2 n)$ is defined, approximate values of $f(x) d x$ can be calculated by the following equations. The equations can be understood from Figure 1.

Trapezoidal rule:

$$
\left[1 / 2 *\left(y_{0}+y_{2 n}\right)+\left(y_{1}+y_{2}+\cdots+y_{2 n-1}\right)\right] *(b-a) / 2 n
$$

Maclaurin's rule:

Simpson's rule:

$$
\left(y_{1}+y_{3}+\cdots+y_{2 n-1}\right) *(b-a) / n
$$

$$
\left[\left(y_{0}+y_{2 n}\right)+4\left(y_{1}+y_{3}+\cdots+y_{2 n-1}\right)+2\left(y_{2}+y_{4}+\cdots+y_{2 n-2}\right)\right] *(b-a) / 6 n
$$

Numerical evaluation of approximate formulas. The magnetic properties of typical non-oriented electrical steel sheets in the specified radial directions were calculated by the approximate formulas (Table 2). The data given for each value of angle represent the magnetic properties of the non-oriented electrical steel sheets in the specified radial direction.

Simpson's rule $\left(0-180^{\circ}\right)$ :

$$
\left(0^{\circ}+2 * 22.5^{\circ}+45^{\circ}+2 * 67.5^{\circ}+90^{\circ}+2 * 112.5^{\circ}+135^{\circ}+2 * 157.5^{\circ}\right) / 12
$$

Simpson's rule $\left(22.5-202.5^{\circ}\right)$ :

$$
\left(22.5+2 * 45^{\circ}+67.5^{\circ}+2 * 90^{\circ}+112.5^{\circ}+2 * 135^{\circ}+157.5^{\circ}+2 * 180^{\circ}\right) / 12
$$

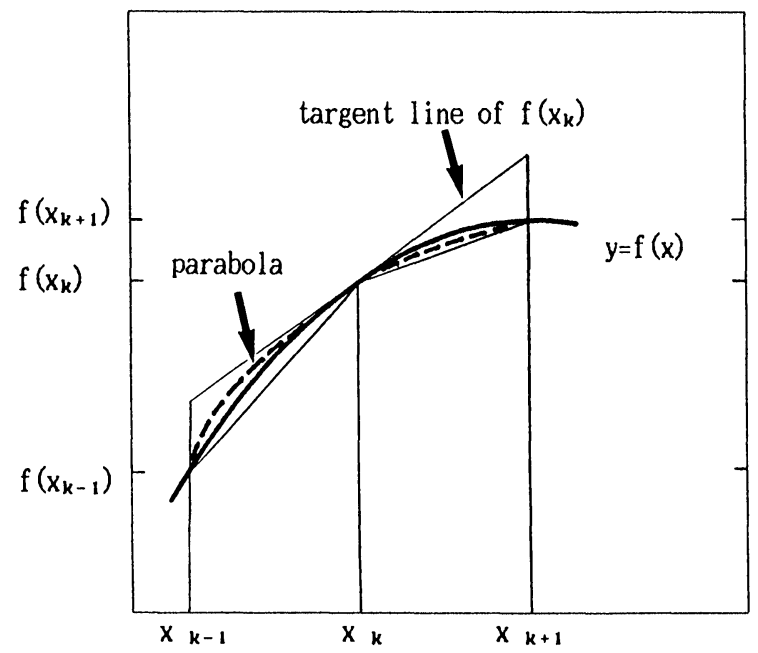

Figure 1 The evaluation of the definite integral by the several rules. 
Table 2 Magnetic properties at each radial direction of typical non-oriented electrical steel sheets which were produced by the different manufacturing processes.

\begin{tabular}{|c|c|c|c|c|c|c|c|c|c|c|}
\hline Position & $\begin{array}{l}\text { Specime } \\
W_{15 / 50} \\
(w / k g)\end{array}$ & $\begin{array}{l}n A \\
B_{50} \\
(T)\end{array}$ & $\begin{array}{l}\text { Specime } \\
W_{15 / 50} \\
(w / k g)\end{array}$ & $\begin{array}{l}n B \\
B_{50} \\
(T)\end{array}$ & $\begin{array}{l}\text { Specim } \\
W_{15 / 50} \\
(w / k g)\end{array}$ & $\begin{array}{l}n C \\
B_{50} \\
(T)\end{array}$ & $\begin{array}{l}\text { Specim } \\
W_{15 / 50} \\
(w / k g)\end{array}$ & $\begin{array}{l}n D \\
B_{50} \\
(T)\end{array}$ & $\begin{array}{l}\text { Specime } \\
W_{15 / 50} \\
(w / k g)\end{array}$ & $\begin{array}{l}n E \\
B_{50} \\
(T)\end{array}$ \\
\hline $0^{\circ}$ & 5.07 & 1.776 & 4.28 & 1.760 & 4.95 & 1.847 & 2.99 & 1.756 & 4.92 & 1.840 \\
\hline $22.5^{\circ}$ & 5.24 & 1.749 & 4.33 & 1.753 & 5.07 & 1.802 & 3.14 & 1.707 & 5.22 & 1.782 \\
\hline $45^{\circ}$ & 5.42 & 1.713 & 4.55 & 1.737 & 5.57 & 1.703 & 3.46 & 1.645 & 5.64 & 1.708 \\
\hline $67.5^{\circ}$ & 5.45 & 1.703 & 4.62 & 1.725 & 5.94 & 1.669 & 3.51 & 1.659 & 5.54 & 1.728 \\
\hline $90^{\circ}$ & 5.31 & 1.723 & 4.61 & 1.724 & 5.74 & 1.683 & 3.38 & 1.697 & 5.33 & 1.768 \\
\hline $112.5^{\circ}$ & 5.43 & 1.703 & 4.58 & 1.728 & 5.87 & 1.669 & 3.49 & 1.659 & 5.55 & 1.727 \\
\hline $135^{\circ}$ & 5.41 & 1.713 & 4.60 & 1.735 & 5.76 & 1.694 & 3.40 & 1.646 & 5.66 & 1.706 \\
\hline $157.5^{\circ}$ & 5.16 & 1.747 & 4.27 & 1.758 & 5.08 & 1.792 & 3.14 & 1.707 & 5.25 & 1.776 \\
\hline$\left(180^{\circ}\right)$ & $(5.07)$ & $(1.776)$ & $(4.28)$ & $(1.760)$ & $(4.95)$ & (1.847) & (2.99) & (1.756) & $(4.92)$ & (1.840) \\
\hline $\mathrm{L}+\mathrm{C}$ & 5.19 & 1.750 & 4.45 & 1.742 & $5.35)$ & 1.765 & 3.19 & 1.727 & 5.13 & 1.804 \\
\hline
\end{tabular}

Trapezoidal rule:

$$
\left(0^{\circ}+22.5^{\circ}+45^{\circ}+67.5^{\circ}+90^{\circ}+112.5^{\circ}+135^{\circ}+157.5^{\circ}\right) / 8
$$

Maclaurin's rule $\left(0-180^{\circ}\right)$ :

$$
\left(22.5^{\circ}+67.5^{\circ}+112.5^{\circ}+157.5^{\circ}\right) / 4
$$

Maclaurin's rule $\left(22.5-202.5^{\circ}\right)$ :

$$
\left.0^{\circ}+45^{\circ}+90^{\circ}+135^{\circ}\right) / 4
$$

Strictly speaking, the circumferential magnetic properties can be evaluated from the data measured at the angles of 0 to $90^{\circ}$, but application of the values measured at the angles between 0 and $180^{\circ}$ results in the increased accuracy of measurement because the magnetic properties in the rolling plane are not perfectly symmetric, as is the case with actual pole figures.

Application of periodic function. The radial magnetic properties in the rolling plane periodically change ever $180^{\circ}$ and hence can be represented by a periodic function or trigonometric function more reasonably than the formulas noted above.

$$
f(\theta)=a_{0}+a_{1} * \cos 2 \theta+a_{2} * \cos 4 \theta+a_{3} * \cos 6 \theta+a_{4} * \cos 8 \theta
$$

where $a_{0}, a_{1}, a_{2}, a_{3}$ and $a_{4}$ are constants that vary from specimen to specimen. For the magnetic induction of specimen $\mathrm{A}$, the coefficients $a_{0}, a_{1}, a_{2}, a_{3}$ and $a_{4}$ can be calculated as follows:

$$
\begin{aligned}
& a_{0}=1.728375 \\
& a_{1}=0.02916230551626605 \\
& a_{2}=0.01824999999999995 \\
& a_{3}=2.662305516265943 * 10^{-3} \\
& a_{4}=2.875000000000027 * 10^{-3}
\end{aligned}
$$

A typical curve for the magnetic induction $B_{50}$ of specimen $A$ is shown in Figure 2. Ultimately, the mean value of a magnetic property in the radial directions can 


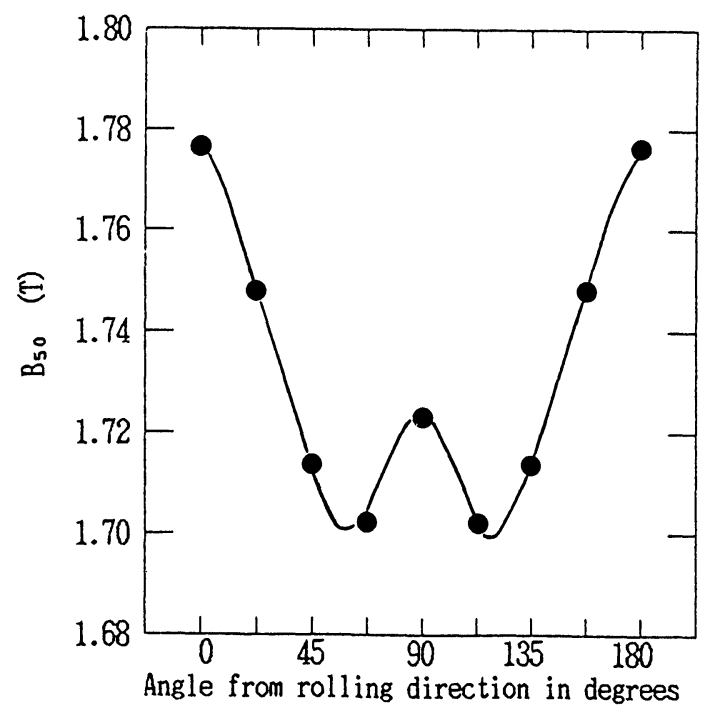

Figure 2 The typical curve of the magnetic induction $B_{50}$ by the trigonometric function (Specimen A).

be obtained by integration between the angles of 0 to $180^{\circ}$, using Eq. (9), and is equal to $a_{0}$.

\section{Measurement of Mognetic Properties on Ring Specimens}

Thirty rings are punched to an outside diameter of $90 \mathrm{~mm}$ and inside diameter of $74 \mathrm{~mm}$, stress-relief annealed, laminated, wound with primary and secondary windings of 200 turns each, and tested for magnetic properties. The inside diameter to outside diameter ratio is set at 0.82 , because if this ratio exceeds 0.82 , the magnetizing force $\mathrm{H}$ will be determined within $1.0 \% .^{3}$

\section{Evaluation of Circumferential Magnetic Properties}

The circumferential magnetic properties calculated by representative integration techniques are compared with the magnetic properties measured on ring specimens in Table 3 . The magnetic properties measured on the ring cores are

Table 3 Magnetic properties available for the circumferential direction.

\begin{tabular}{|c|c|c|c|c|c|c|c|c|c|c|}
\hline & \multicolumn{2}{|c|}{ Specimen $A$} & \multicolumn{2}{|c|}{ Specimen B } & \multicolumn{2}{|c|}{ Specimen $C$} & \multicolumn{2}{|c|}{ Specimen D } & \multicolumn{2}{|c|}{ Specimen $E$} \\
\hline & $\begin{array}{l}W_{15 / 50} \\
(w / k g)\end{array}$ & $\begin{array}{l}B_{50} \\
(T)\end{array}$ & $\begin{array}{l}W_{15 / 50} \\
(w / k g)\end{array}$ & $\begin{array}{l}B_{50} \\
(T)\end{array}$ & $\begin{array}{l}W_{15 / 50} \\
(w / k g)\end{array}$ & $\begin{array}{l}B_{50} \\
(T)\end{array}$ & $\begin{array}{l}W_{15 / 50} \\
(w / k g)\end{array}$ & $\begin{array}{l}B_{50} \\
(T)\end{array}$ & $\begin{array}{l}W_{15 / 50} \\
(w / k g)\end{array}$ & $\begin{array}{l}B_{50} \\
(T)\end{array}$ \\
\hline Maclaurin $0-180^{\circ}$ & 5.320 & 1.7255 & 4.450 & 1.7410 & 5.490 & 1.7330 & 3.320 & 1.6830 & 5.390 & 1.7533 \\
\hline Simpson $0-180^{\circ}$ & 5.314 & 1.7274 & 4.470 & 1.7403 & 5.495 & 1.7326 & 3.316 & 1.6840 & 5.389 & 1.7540 \\
\hline Trapezoid & 5.311 & 1.7284 & 4.480 & 1.7400 & 5.498 & 1.7324 & 3.314 & 1.6845 & 5.389 & 1.7544 \\
\hline Simpson $22.5-202.5^{\circ}$ & 5.308 & 1.7293 & 4.490 & 1.7396 & 5.500 & 1.7322 & 3.312 & 1.6850 & 5.388 & 1.7548 \\
\hline Maclaurin $22.5-202.5^{\circ}$ & 5.302 & 1.7313 & 4.510 & 1.7390 & 5.505 & 1.7318 & 3.308 & 1.6860 & 5.388 & 1.7555 \\
\hline Trigonometric function & 5.311 & 1.7284 & 4.480 & 1.7400 & 5.498 & 1.7324 & 3.314 & 1.6845 & 5.389 & 1.7544 \\
\hline Ring core & 5.372 & 1.7359 & 4.515 & 1.7518 & 5.543 & 1.7428 & 3.266 & 1.6972 & 5.467 & 1.7615 \\
\hline
\end{tabular}




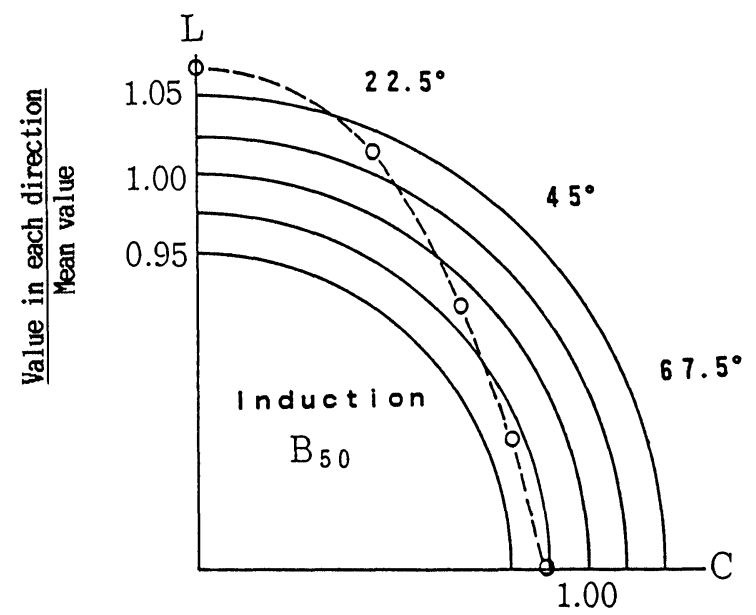

Figure 3 The graphic representation of magnetic induction in the radial directions.

found to be practically the same as those algebraically calculated in each of the specified radial directions. The value of $a_{0}$ in Eq. (9) is demonstrated to be equivalent to the value calculated by the trapezoidal formula. The value calculated by the trapezoidal formula is regarded as the most preferred value and is located intermediate between the algebraically calculated values.

\section{Graphic Representation of Radial Magnetic Properties}

The radial distribution of a magnetic property can be represented in the form of a quadrant where the magnetic property is expressed as a ratio of the radial mean value to the value measured in each of the specified radial directions, as shown in Figure 3. The amount of anisotropy of the magnetic property in the rolling plane of the sheet is illustrated in the quadrant. This graphic representation allows the relationship between the texture and anisotropy of magnetic properties to be visually understood.

\section{TEXTURES AND MAGNETIC PROPERTIES}

\section{Circumferential Magnetic Properties and LC Magnetic Properties}

The LC magnetic properties measured on half-lengthwise and half-transverse specimens do not accurately represent the magnetic properties of non-oriented electrical steel sheets used to make motor cores. Figure 4 and 5 show the relationship between the LC magnetic properties and circumferential magnetic properties of typical non-oriented electrical steel sheets. The differences between the LC and circumferential magnetic properties are more clearly evident in non-oriented electrical steel sheets with large anisotropy than those with randomly oriented grains. The differences between the LC and circumferential magnetic properties are smaller when the non-oriented electrical steel sheets are manufactured by the conventional temper rolling process. These non-oriented 


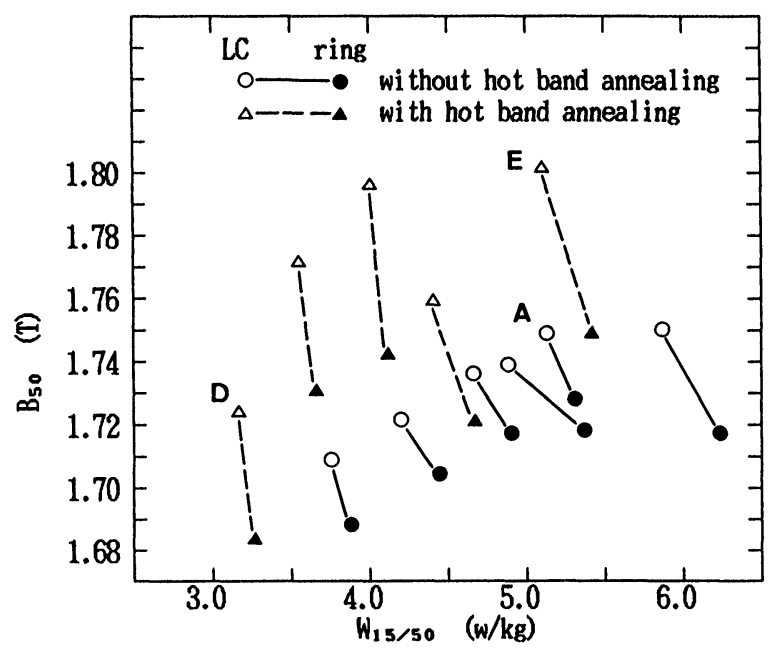

Figure 4 The relationship between LC magnetic properties and circumferential magnetic properties of single-reduction cold rolled products.

electrical steel sheets thus have a best distribution of magnetic properties for motor applications. The magnetic induction of non-oriented electrical steel sheets produced by the special hot band annealing and single-reduction cold rolling process is at high levels despite the marked differences between the LC and circumferential magnetic properties.

\section{Textures and Radial Magnetic Properties}

Several attempts have been reported to clarify the magnetic anisotropy of non-oriented silicon steel sheets. ${ }^{, 5,6,7}$ The relationship between the textures and

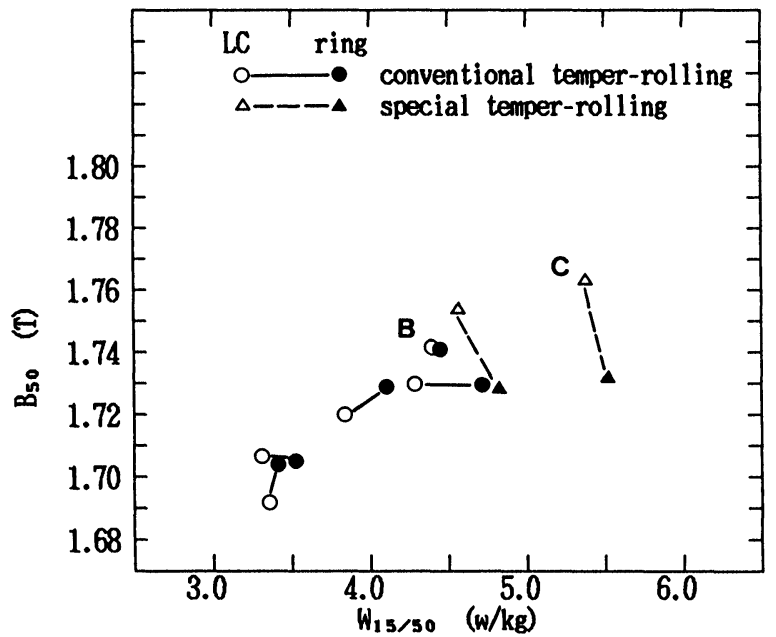

Figure 5 The relationship between LC magnetic properties and circumferential magnetic properties of temper-rolled products. 
magnetic properties in each of the specified radial directions of the rolling plane is of interest to the researchers of non-oriented electrical steel sheets. Figure 6 shows the pole figures and quadrant magnetic property distributions of five representative specimens manufactured by different processes. Process 1 (specimen $\mathrm{A}$ ) is a simple, single-reduction cold rolling process and provides a relatively uniform distribution of core loss and magnetic induction. This process, however, results in poorer magnetic properties than the other processes because the amount of grains with the $\{554\}\langle 225\rangle$ preferred orientation is larger. Process 2 (specimen B) is a conventional temper rolling process and provides an optimum distribution of magnetic properties for motor applications. For the texture of the temper-rolled product exhibits a random distribution rather than an anisotropic

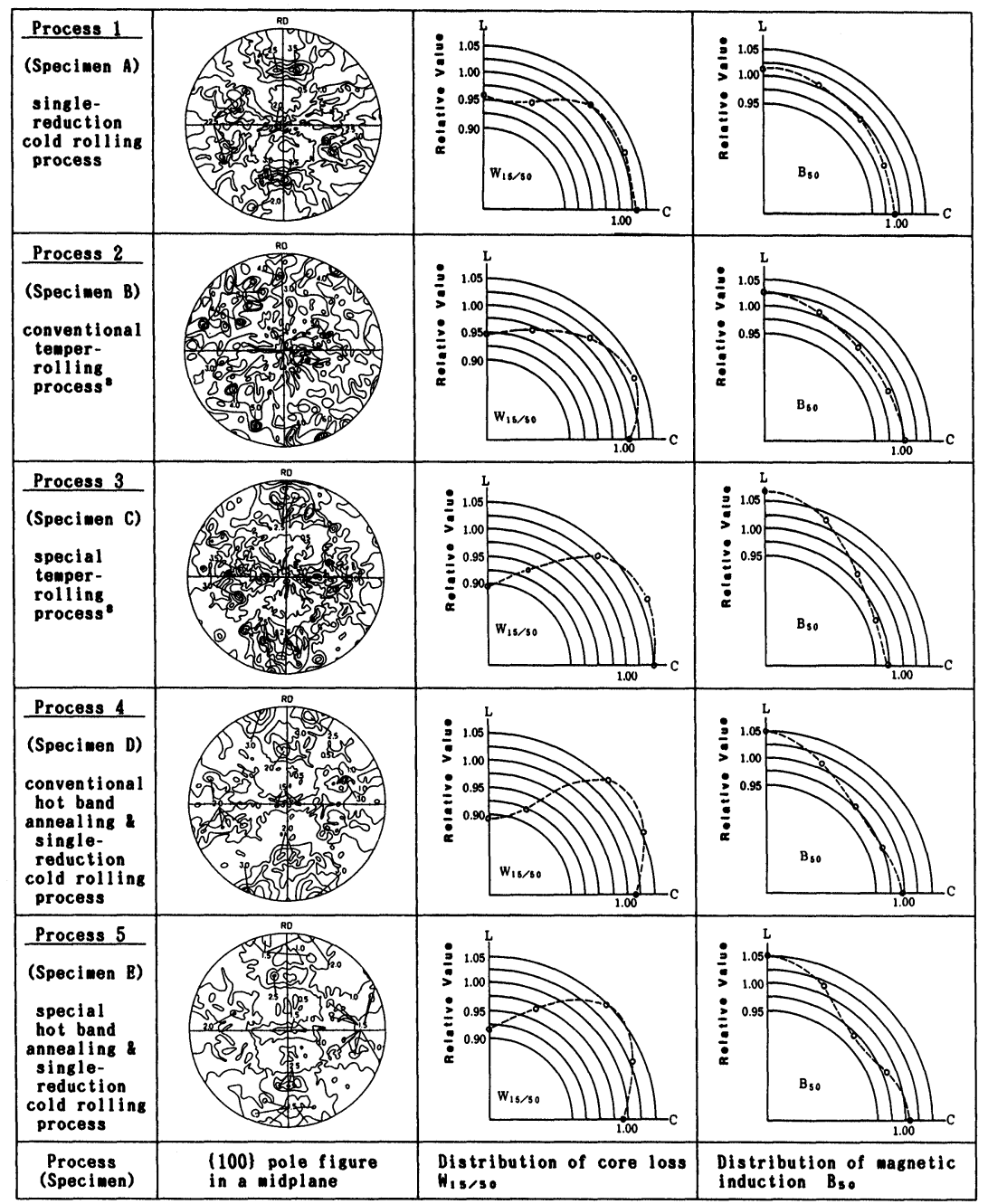

Figure 6 The relationship between textures and distribution of magnetic properties on the plane of typical non-oriented electrical steel sheets. 
distribution. Process 3 (specimen $C$ ) is a special temper rolling process and develops a texture close to the (110)[001] texture by strain-induced preferred grain growth. ${ }^{8}$ The special temper rolling process is thus suited for producing non-oriented electrical steel sheets for transformers and fluorescent lamp ballasts. Process 4 (specimen D) is a conventional hot band annealing and single-reduction cold rolling process and develops a weak (110)[001] texture by primary recrystallization and normal grain growth. Generally, silicon steels that contain $2 \%$ or more silicon are manufactured by this process. Process 5 (specimen E) is a special hot band annealing and single-reduction cold rolling process and slightly develops a texture close to the (100)[001] texture by the combined effect of steel composition and hot band annealing. This process can relatively easily produce silicon-free electrical steel with a weak (100)[001] texture but when it is employed to manufacture silicon steel, some device must be incorporated, such as addition of antimony ( $\mathrm{Sb}$ ) to molten steel. ${ }^{9}$ The process is suited for manufacturing non-oriented electrical steel sheets that are suitable for static machine applications where magnetic properties in the transverse direction are especially important but not suitable for motor applications. For cube-textured sheets are high in magnetic induction in the circumferential direction but are anisotropic with respect to magnetic induction in the radial directions.

\section{Texture Changes in Normal Direction}

Changes in the pole densities of non-oriented electrical steel sheets in three representative positions in the normal direction are shown in Table 4. Specimen $B$ with a uniform distribution of magnetic properties in the rolling plane and manufactured by process 2 exhibits a homogeneous distribution of pole densities in the normal direction as well. Specimen $\mathrm{C}$ is more uneven in the distribution of pole densities in the normal direction than other specimens but does not look like a sheet with anisotropy according to this table, because it contains a small number of the (110)[001] pure grains. The pole density information is not very helpful, therefore. The pole density intensity of specimen $\mathrm{C}$ is higher at the quarter point (Figure 7) than at the center (Figure 6). A temper rolling process is proposed for manufacturing grain oriented electrical steel sheets, ${ }^{10}$ but grain oriented electrical steel sheets with high (110)[001? grain intensity are not yet produced by such a process. Generally, texture changes in the normal direction are more or less observed in steel sheets. This phenomenon depends on the hot rolling step of the steel production process. ${ }^{11}$ Strictly speaking, therefore, it is difficult to discuss the

Table 4 Changes in the pole densities in three positions in the normal direction of typical non-oriented electrical steel sheets.

\begin{tabular}{lllllllllllll}
\hline \multicolumn{3}{c}{ Surface layer } & \multicolumn{4}{c}{ 1/4 layer } & \multicolumn{1}{c}{ Midplane } \\
& 110 & 100 & 211 & 111 & 110 & 110 & 211 & 111 & 110 & 100 & 211 & 111 \\
\hline Specimen A & 0.26 & 0.94 & 2.12 & 8.81 & 0.14 & 0.94 & 1.60 & 5.02 & 0.14 & 1.47 & 1.70 & 4.41 \\
Specimen B & 0.55 & 1.16 & 0.86 & 1.33 & 0.45 & 0.74 & 0.75 & 1.15 & 0.45 & 1.10 & 1.27 & 1.13 \\
Specimen C & 0.81 & 1.16 & 1.62 & 1.54 & 0.35 & 0.87 & 1.52 & 2.05 & 0.58 & 1.03 & 2.09 & 2.01 \\
Specimen D & 0.86 & 2.37 & 1.40 & 3.41 & 0.55 & 1.23 & 0.78 & 2.03 & 0.57 & 1.68 & 0.82 & 2.51 \\
Specimen E & 1.16 & 2.11 & 0.82 & 2.92 & 0.90 & 1.57 & 0.98 & 3.86 & 0.76 & 2.48 & 1.17 & 3.13 \\
\hline
\end{tabular}




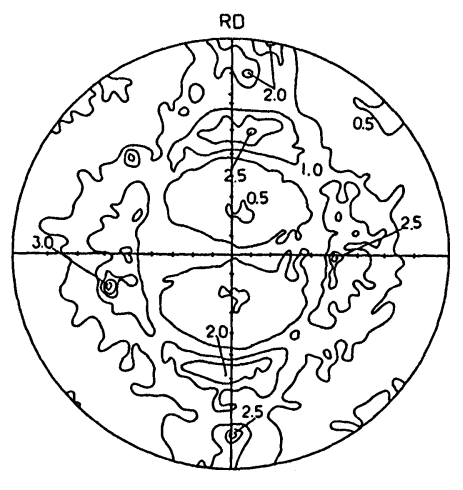

Figure $7\{100\}$ pole figure in a depth of $25 \%$ of the thickness (specimen C).

relationship between the textures and magnetic properties of non-oriented electrical steel sheets.

\section{Ideal Textures and Circumferential Magnetic Properties}

To evaluate the mean magnetizing force in the rolling plane and ideal texture, the values of magnetic induction are calculated from the magnetization curves of single crystals of iron and iron-silicon alloy (Table 5 and Figure 8). ${ }^{5}$ These data show that the isotropic texture provides higher magnetic induction than the (111)[uvw] texture and (110)[uvw] texture. As is naturally expected, the $(100)[0 \mathrm{vw}]$ texture has the highest magnetic induction. For a double-oriented electrical steel sheet that has an almost ideal (100)[001] texture and contains $3.2 \% \mathrm{Si}, B_{25}=1.746 \mathrm{~T}$ and $B_{50}=1.793 \mathrm{~T}$ in ring cores. The effect of the steel silicon and aluminum contents on the mean magnetic induction of the $(100)[0 \mathrm{vw}]$ ideal texture was calculated by regression equations from the data of Table 5 and from the $1.746 \mathrm{~T}$ of the $3.2 \% \mathrm{Si}$ steel. The mean magnetic induction of each specimen in the circumferential direction of the rolling plane is evaluated with respect to the magnetic induction of the (100)[0vw] ideal texture in Table 6 . When the ratios of the Table 6 are taken into account, it can be understood that specimen $E$ with the weak (100)[001] texture is closest to the (100)[0vw] ideal texture. The ratio of $B_{25}$ with a given texture to $B_{25}$ with the (100)[0vw] ideal texture is $84.6 \%$ for the (111)[uvw] texture, $88.3 \%$ for the (110)[uvw] texture and

Table 5 Calculated $B_{35}$ (Tesla) values for ideal plane textures and the isotropic state from iron single crystal data of the $\langle 100\rangle$ and the $\langle 111\rangle$ directions. ${ }^{5}$

\begin{tabular}{lllll}
\hline Si $w t \%$ & 0 & 0 & 0.3 & 3.8 \\
\hline$\langle 100\rangle$ & 2.06 & 2.09 & 2.06 & 1.97 \\
$\langle 111\rangle$ & 1.34 & 1.33 & 1.33 & 1.27 \\
$(100)[0 \mathrm{vw}]$ & 1.79 & 1.81 & 1.78 & 1.71 \\
(111)[uvw] & 1.52 & 1.52 & 1.51 & 1.45 \\
(110)(uvw] & 1.58 & 1.59 & 1.58 & 1.51 \\
isotropic & 1.63 & 1.64 & 1.62 & 1.55 \\
\hline
\end{tabular}




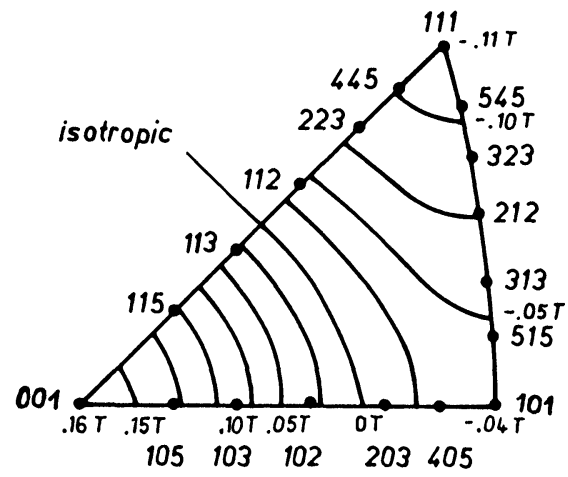

Figure 8 Change of the $B_{25}$ values compared to the isotropic state for ideal plane textures in the orientation triangle of the normal direction. ${ }^{5}$

Table 6 Relative ratios of magnetic induction $B_{25}(\mathrm{~T})$ of the typical processing steel sheets to the (100) $[0 \mathrm{vw}]$ ideal texture.

\begin{tabular}{llll}
\hline & Ring & Ideal & Relative ratio \\
\hline Specimen A & 1.6484 & 1.7903 & $92.07 \%$ \\
Specimen B & 1.6647 & 1.7903 & $92.98 \%$ \\
Specimen C & 1.6516 & 1.7963 & $91.94 \%$ \\
Specimen D & 1.6092 & 1.7465 & $92.14 \%$ \\
Specimen E & 1.6731 & 1.7963 & $93.14 \%$ \\
\hline
\end{tabular}

90.8\% for the isotropic texture, as shown in Table 5. It is interesting, therefore, that the ratios of magnetic properties in these specimens are actually larger than those in the isotropic texture.

\section{SUMMARY}

1. A method is proposed for evaluating the relationship between magnetic properties measured in each of the specified radial directions and the circumferential magnetic properties calculated by the trapezoidal rule. The magnetic properties calculated by the trapezoidal formula are the most reasonable values and are in fact equal to the magnetic properties measured on ring cores.

2. It is made clear that the differences in the distribution of magnetic properties between the radial directions of the rolling plane depend on the manufacturing processes employed.

3. Non-oriented electrical steel sheets with most isotropic magnetic properties can be manufactured by a conventional temper rolling process, but non-oriented electrical steel sheets with the highest magnetic induction can be produced by a process composed of special hot band annealing and single-reduction cold rolling, despite the fact that they have an anisotropic texture close to the (100)[001] texture.

4. The magnetic properties in the circumferential direction achieved with 
commercial non-oriented electrical steel sheets are about $93 \%$ of those obtainable with the $(100)[0 \mathrm{vw}]$ ideal texture.

\section{ACKNOWLEDGMENT}

The authors are grateful to Mr E. Hagiwara for his cooperation in their magnetic measurement of ring cores.

\section{References}

1. ASTM standards A677-84, A683-84, A726-85.

2. JIS C2550-1986.

3. ASTM standards A596-69 (Reapproved 1979).

4. Gol'dshteyn, V. Y. and Verbovetskaya, D. E. (1981). Fiz. Metal. Metalloved., 52, 4, 818-822.

5. Klemm, P., Schlafer, D., Betzl, M. and Hennig, K. In Proceedings of the Sixth International Conference on Textures of Materials, p. 910-917, The Iron and Steel Institute of Japan, 1981.

6. Morris, P. R. and Flowers, J. W. (1981). Texture of Crystalline Solids, 4, 129-141.

7. Page, J. H. R. (1984). IEEE Trans. Magn., MAG-20, p. 1542-1544.

8. Shiozaki, M. (1985). Presented at the Conference on Properties and Applications of Magnetic Materials, Chicago, May 22-24.

9. Shimanaka, H., Ito, Y., Irie, T., Matsumura, K., Nakamura, H. and Shono, Y. (1981). In Energy Efficient Electrical Steels, ed. A. R. Marder and E. T. Stephenson, p. 193-204, TMS-AIME.

10. Jackson, J. M. U.S. Patent 2,535,420.

11. Matuo, M., Sakai, T. and Suga, Y. (1986). Metall. Trans. A, 17A, 1313-1322. 